\title{
Rene Descartes: A distinção da alma e do corpo
}

Joana D’Arc Aguiar ${ }^{1}$

RESUMO: O presente ensaio representa uma contribuição com a reflexão no que a dúvida da alma e do corpo representa em sua imaginação. O objetivo não é exaurir o argumento sobre o tema, mas sim colocar a proposta de um debate que exponha a distinção da alma no corpo, pois envolve uma discussão que se entende a partir da obra de Descartes (1596-1650), O discurso do método, e assim pretende-se debater como se dá a semelhança e a diferença entre o corpo e a alma e suas aplicações filosóficas. De início, será investigado o que se entende’ por corpo e como ele é organizado, em seguida será exposto o que se entende por alma e também como é sua organização e assim será possível que possa haver uma relação ente o corpo e a alma respeitando as suas diferenças. Essa teoria não se preocupa em definir a complexidade da substância pensante ou extensa, mas muito mais em explicar como uma age sobre a outra. Como é possível que a alma, uma substância constituída de uma matéria e com contorno espaciais seja claramente delimitada? Segundo Descartes, a alma está vinculada com o corpo, o que é um erro comum de interpretações pouco aprofundadas o entendimento de que o corpo tem pensamentos e não que o eu (corpo e alma) é o próprio pensamento em sua manifestação. Segundo Descartes, na correspondência que relata nas Meditações, o intuito era primeiramente conceber a noções que apareciam somente na alma e que são distintas das que apreciam somente o corpo, eis um problema filosófico para entender como o filósofo respondeu.

Palavras chave: Descartes; Corpo; Alma; Pensamento.

\section{Introdução}

O presente texto tem como objetivo traçar uma comparação entre a filosofia e a distinção da alma e do corpo, como termo que se refere ao corpo é uma parte indefinida extensa em três dimensões. Se o corpo é desligado após a morte, logo ele é um objeto de estudo e com isso é uma máquina destituída de sua identidade. O estudo cartesiano é se o corpo é uma máquina criada por Deus e se as suas funções dependem dos órgãos para funcionar, o corpo entrega o controle das ações para a alma. Em $A$ distinção real entre corpo e mente poderia parecer que Descartes queria referir-se à distinção entre o Eu e a alma, na qualidade de substância pensante, ou seja, este corpo em que habito é, por outro lado, a distinção entre uma substância pensante e o corpo em geral. Do racionalismo de Descartes, como o sujeito que duvida de tudo e começa a conhecer a distinção da alma e corpo, a primeira verdade que se dá é seguir ao cogito. Pois o sujeito que duvida, pensa e existe, para Descartes isso é aprofundar o conhecimento desse sujeito

\footnotetext{
${ }^{1}$ Graduanda em Filosofia pela Cead-UFPI polo Juazeiro - BA
} 
que existe para encontrar outras verdades nele próprio. Quando uma substancia é pensante e não diz respeito ao corpo.

\section{O método na análise corpo e alma}

Descartes fala que a imaginação tem forma inusitada e que atribuímos tudo a natureza e que a imaginação é perdulário ${ }^{2}$, pois ela tem a capacidade de inventar e imaginar de tal modo que nada antes visto se assemelha, pois, o fictício que é falso com a imaginação é assimilado parecendo ser verdadeiro.

É certo que existe e que consiste a minha existência? O que sou eu? Quem é neste momento uma substância exclusiva pensante? Quando um sujeito é puramente racional, segundo Descartes, não pode ser uma substância que contém o corpo, porque no segundo o nível da dúvida, se põe em causa toda a realidade sensível e essa suspeita ainda permanece com a existência da dúvida do próprio corpo. Não posso duvidar da existência do sujeito pensante ou da alma, logo sou uma substância pensante. Contudo, ao descobrir a minha essência ${ }^{3}$, descubro também a distinção entre a alma e o corpo. Não sabendo se existem realmente os corpos, sei que existo enquanto eu penso, existo como uma substância pensante. Portanto, a existência da alma ou do pensamento é totalmente independente do corpo.

Essa distinção da alma e corpo vai ser verdadeiramente anti-Aristotélica, posto que separa radicalmente o material do espiritual. Assim, o sujeito pensante é um ser mais imperfeito, continuando com a reflexão sob a alma e o corpo, procura conhecer mais profundamente a si mesmo. O sujeito pensante vai descobrir que é imperfeito, neste momento, o percurso reflexivo com o plano cartesiano mostra que a própria dúvida é uma imperfeição, e um sinal de que sou limitado e que em termos do conhecimento, a dúvida tem um suporte que é o sujeito pensante finito.

Descartes mostra que a existe uma compreensão do corpo, mesmo que a alma seja mais fácil de compreender. Com a obrigação de se fazer o uso da razão, para que o corpo não seja confundido, é muito difícil de conhecer o corpo, pois por si só, está sujeito ao engano e ao erro de que a alma é inteiramente distinta do corpo. Por quê? É justamente aí o aspecto da racionalidade de Descartes que o corpo é uma máquina que foi construída por Deus, logo é ele

\footnotetext{
2 Perdulário; diz se que é uma pessoa que gasta em excesso.

${ }^{3}$ Essência; como a "razão, natureza, forma, definição formal de algo" sendo assim podemos dizer, que a essência de um círculo é ser uma figura plana descrita por um ponto dado, ou uma figura tal que todos os pontos em sua circunferência sejam equidistantes do centro. Substância ; Aristóteles definiu substancia como "aquilo que não se pode afirmar de um sujeito ou em um sujeito, como, exemplo ,um determinado homem ou um cavalo"(Das categoria 2 a 21).
} 
mesmo substância extensa e sensível, e se o corpo para, vai restar só a matéria dele próprio. A razão da dúvida é segura, pois sem a razão, o corpo não teme a dúvida da existência e por isso é mais fácil conhecer a alma do que o corpo.

Segundo Descartes, não há segurança ao afirmar qualquer coisa além do cogito, o que parece ser nesse momento, é que ao se aproximar de um objeto totalmente diferente do que antes foi percebido, a mente parece não ter nenhuma relação entre o corpo e a alma, mediante isso, Descartes admite uma união existente entre o corpo e alma. Essa união tira uma particulidade do corpo, concebida como uma máquina organizada, e da alma, concebida como pensamento que um complementário ao corpo. Que o pensamento dá sentido ao funcionamento do corpo. Assim não é possível haver um significado no homem se falta a alma ou o corpo. Contudo, não basta estarmos alojados a um corpo humano, porque assim como um motorista sem seu carro não sai do lugar, é necessário que esteja tudo interligado e unido estritamente na área corpórea para que ele seja governado pela alma.

\subsection{Primeira parte método}

O projeto de Descartes revela que parte do método está procurando a existência de deus e da alma, separando do corpo que acrescenta várias outras coisas que não são consideradas agradáveis. Como exemplo, não é verossímil que todos se enganem, mas bem claro é a distinção que demostra a certeza de sua própria existência na qualidade de "coisa pensante", porque na descoberta de uma ideia clara distinta que estabelece tudo aquilo que percebo clara e distantemente como verdadeiro. O poder de julgar (juízo da filosofia escolástica fez uma distinção entre de um lado que percebe o conteúdo de uma proposição e de outro julgar como falso ou verdadeiro) é distinguir o verdadeiro do falso, que é propriamente o que denomina o bom senso ou a razão. Isto é por natureza igual em todos os seres humanos, ainda que a diversidade de nossas opiniões não passe da diversidade que decorre de seres mais razoáveis que os outros, e que somente conduzimos em nossos pensamentos por diversas mensagens transmitidas. Segundo Descartes, o proposito dele não é de ensinar o método do que cada um deve seguir para o bem conduzir de sua razão, mas ele mostra de que modo ele se acha mais hábil do que aqueles a quem os dão preceitos.

\subsection{Segunda parte do método}


A religião de Descartes está sempre em seus pensamentos, como assim também as leis que ele imaginou que o povo, tendo-se civilizado, teriam apenas pouco a pouco incorporado na medida que a incomodidade da ignorância a isso os forçou. Com a verdadeira religião, cujos mandamentos eram ter Deus como ser incorporável e bem regulamentado. Descartes se distinguiu como um homem que resolveu caminhar lentamente por usar tanta circunspecção em todas as coisas que, embora só avançasse muito pouco, pelo menos evitaria rejeitar totalmente opiniões que tivessem alguma verdade em potencial.

A crença dele foi introduzida pela razão, pois ele teve bastante tempo em projetar a sua obra que empreendeu o conhecimento de todas as coisas de que o espírito daquele tempo seria capaz.

Me persuadi de que não teria cabimento um particular propor-se a reformar um Estado mudando-lhe tudo desde os alicerces e derrubando o para reerguê-lo; nem mesmo também reformar o corpo da ciência ou a ordem estabelecida nas escolas para ensinálas.) (DESCARTES, 1996, p. 18).

Segundo Descartes, havendo apenas uma verdade de cada coisa, quem quer que a encontre sabe dela tudo o que se pode saber; exemplo uma criança instruída em aritmética, tendo feito uma adição de acordo com suas regras, pode estar seguro de ter encontrado, sobre a soma que examinava tudo o que o espirito humano poderia encontrar.

\subsection{Terceira parte do método}

Antes de começar a reconstruir a casa onde moramos, não basta demolir e prover da matéria a um arquiteto, ou nós mesmos exercemos a arquitetura e, além disso, ter-lhe traçado cuidadosamente a planta, ou também é preciso providenciar a outro lugar onde nos possamos alongar comodamente enquanto dura o trabalho. Assim, deve permanecer firme em nossas ações enquanto a razão obrigar a sê-lo em juízo, o ato de não deixar de viver com uma moral provisória que consiste em três ou quatro máximas.

A primeira máxima que ele apresentou obedece às leis e aos costumes do país, conservando com constância a religião na qual Deus é o criador de tudo e acreditamos assim em tudo em sua fé. Descartes começa a levar em conta as próprias as opiniões de Deus, porque queria submeter todas ao exame, estava certo de que nada melhor poderia seguir e ser mais sensato. Parecia ser mais útil seguir aqueles que com quem teria de viver a saber quais seriam as verdadeiras opiniões, que deviam atentar mais à pratica do que diziam porque dada a essa corrupção de costumes, há poucas pessoas que dizem tudo que crêem. Muitos ignoram com a ação do pensamento pela qual cremos uma coisa, é diferente daquela pela qual sabemos que cremos. 
A segunda máxima era ser mais firme e dirimido do que pudesse em ações e não seguir com menos constância as opiniões duvidosas, uma vez que por elas tiver se determinado, que a partir disso fossem seguras.

A terceira máxima é tentar vencer a si mesmo e modificar antes o desejo que a ordem do mundo. Não há nada que esteja inteiramente em nosso poder, a não ser o nosso pensamento. As três máximas justificam-se pelo propósito de instruir, pois tendo Descartes uma luz para diferenciar o verdadeiro do falso, ele acredita que não deve se contentar um só momento com as opiniões dos outros. Se não tivesse proposta de empregar o juízo, em fim não teria de se limitar aos desejos, nem constatar, se não tivesse seguido o caminho de todos os conhecimentos que seria capaz. Pensava está-lo também de que só a ação de todos os bens verdadeiros estava ao alcance.

Após ter assegurado as máximas, e tê-las posto com a verdade da fé, que sempre foram as primeiras sem suas crenças que julga que quando todas outras opiniões poderiam livremente ser desfeitas. A quarta máxima de Descartes refere ao que o melhor resultado das outras três é estar convivendo com os homens do que permanecendo tempo fechado no quarto aquecido com todos esses pensamentos.

\subsection{Quarta parte de método}

Ela fala das primeiras meditações ${ }^{4}$ que Descartes fez, pois elas são uma forma de metafísica pouco comum à época e que talvez não sejam do agrado de todos, a fim de julgar se os fundamentos que toma são bastante firmes. O paralogismo ${ }^{5}$ que julgando o sujeito ao erro rejeita como falsas todas as razões que antes tomara como demonstração e finalmente considerando que todos pensamentos estão de acordo, pode ocorrer quando dormimos, sem que nenhum seja verdadeiro. Com isso, ele resolve fingir que todos os pensamentos não eram mais verdadeiros que as ilusões de sonhos. Mas logo atenta que enquanto pensar que a verdade "penso, logo existo" afirma tão certo como todas as extravagantes suposições de céticos que não eram capazes de serem abaladas: foi assim o primeiro princípio da filosofia cartesiana. Com isso, examinando o que era e vendo que pode fingir que não tem nenhum corpo e que não havia nenhum mundo, nem lugar algum, foi pelo fato d 'Eu' pensar e imaginar o verdadeiro, que a minha essência

\footnotetext{
${ }^{4}$ Meditações; É demostrada a existência de Deus e a distinção, real a mente e o corpo; Há uma importância considerável a escolha que Descartes faz em o titulo "Meditações" para apresentação diferente de seu sistema metafisico.

${ }^{5}$ Paralogismo; E um raciocino falacioso, ou seja, falso, mas que tem aparência de verdade. Logo é raciocino falso que se estabelece involuntariamente.
} 
necessita de um lugar, uma res extensa. Quando refiro o 'Eu', isto é a alma, pela qual somos o que somos.

\section{CONCLUSÃO}

Esta perspectiva de compreender o conhecimento que Descartes fala com a real distinção existente da alma do corpo, faz com que entendemos o problema e a certeza de suas Meditações sobre o ser humano. $\mathrm{Na}$ sua visão, ele acredita que o ser humano é a união entre o corpo e a alma, portanto, quando ele fala da alma, refere-se sobre o conhecimento do eu, logo ele atribui o fato de existir o pensamento que liga o corpo e alma como um só. Segundo Descartes, afirmar que "a natureza da matéria, ou do corpo considerado em geral (corpus in universum spectatum) consiste unicamente em um ser algo extenso em comprimento, largura e profundidade (DESCARTES, 1988, p. 87) faz adotar, com efeito, uma posição ontológica dualista quanto ao "corpo" neste sentido geral: o mundo físico constitui-se por apenas uma substância indefinidamente divisível, e o fato de ser comum recortamos o mundo ${ }^{6}$ em objetos individuais não significa que haja uma real pluralidade substancial.

\section{REFERÊNCIAS}

COTTINGHAM, JOHN. Dicionário de Descartes. Tradução: Helena Martins. Rio de janeiro: Jorge Zahar Ed. 1995.

DESCARTES, RENÉ. Discurso do Método: para bem conduzir a própria razão e procurar a verdade nas ciências. Tradução Maria Ermantina Galvão. São Paulo: Martins, 1996.

\footnotetext{
6 "Mundo; (que na verdade constitui a primeira parte originalmente continuando do qual o que hoje conhecemos como o tratado sobre o homem constituía a parte final) apresenta uma explicação geral do princípio cartesiano da física e da cosmologia para então aplica-la a explicação da formação do sol, das estrelas e dos planetas, da terra e da lua bem como da natureza." (COTINGHAN, 1995, p. 47).
} 